\title{
Embryo Transfer in Upper Uterine Cavity versus Mid-Uterine Cavity in Cases of Previous Failed Implantation
}

\author{
Abdel-Rahman Anbar* and Eman A H \\ Department of Obstetrics and Gynecology, Al-Azhar University, Egypt
}

Submission: August 16, 2017; Published: August 22, 2017

*Corresponding author: Abdel-Rahman Anbar, Faculty of Medicine, Al-Azhar University, Egypt, Email: mohammedelsokkary1@yahoo.com

Abstract

Objective: The aim of this work is to compare site of embryo transfer in mid-uterine cavity versus site of embryo transfer in upper uterine cavity in cases of previous failed implantation following ICSI treatment protocol.

Design: A prospective study. Setting: private IVF center (walad and bent). Patients and methods: Sixty two infertile women undergoing ICSI, were recruited from Assisted Reproductive Technology Unit (ART hospital department), during the period between December 2015 to October 2017.

Results: The miscarriage rate was not significantly higher in case of embryo deposition close to the fundal endometrial surface (EFD $<5 \mathrm{~mm})$; as a consequence, in this subgroup of women the ongoing pregnancy rate at 10 weeks was lower than the one observed for between 5 and $15 \mathrm{~mm}$. The ongoing pregnancy rate was higher in group I than group II due to a significantly less implantation rate, $<5 \mathrm{~mm}$ it was lower due to a relevantly higher miscarriage rate.

Conclusion: In conclusion, it appears that embryo transfer between 5 and $15 \mathrm{~mm}$ from the uterine fundus, is the place where most pregnancies obtained with spontaneous conception may be found during the first US examination at 6-7 weeks, and is likely to be the place where the endometrium displays the best receptivity.

Keywords : Embryo transfer; ICSI; Assisted reproductive technology; Endometrium; Luteal phase; Follicular phase

\section{Introduction}

Infertility is the failure of a couple to conceive after one year of regular non protective intercourse. Infertility is a global health issue, affecting approximately 8-10\% of couples worldwide [1]. Since 1978, ART (assisted reproductive technology) procedures have been used to overcome many causes of infertility. ART procedures include those infertility treatments in which the eggs and/or the sperms are handled in the laboratory for the purpose of establishing a pregnancy (i.e., in-vitro fertilization [IVF-ET] and related procedures). Since the birth of the U.S. first infant conceived with ART in 1981, use of these treatments has increased dramatically. Each year, both the number of medical centers providing ART services and the total number of procedures performed have increased notably [2].

IVF (In-Vitro Fertilization)/ICSI (Intra cytoplasmic Sperm Injection) has been the treatment of choice in severe tubal infertility and for most other indications (male factors, ovarian dysfunction, tubal disease, endometriosis and uterine or cervical factors); IVF is applied as the last resort therapy after the failure of other treatment modalities [3]. Embryo transfer (ET) is the final and the most critical step in assisted reproduction, despite its relative simplicity. It is considered of utmost importance in maximizing the chances of achieving pregnancy [4]. It is routinely done through the transcervical route and is associated with multiple potential negative factors [5]. It has shown marked variability among different IVF programs, and also among physicians within the same program [6].

The goal of a successful ET is to deliver the embryos traumatically to a location in the uterus where implantation is maximized. Potential reasons for a failed transfer include disruption of the endometrium by the catheter, induction of uterine contractions, deposition of the embryos in a suboptimal location, or damage to the embryos during the process [7]. The majority of women undergoing IVF reach embryo transfer (ET) stage, with good quality embryos available for transfer, but only a small proportion of them will ever achieve a clinical pregnancy or live birth [8]. Various factors are involved in 


\section{Global Journal of Reproductive Medicine}

optimizing the success of the process of embryo transfer. Some factors are considered before embryo transfer, others during the process itself, and additional factors influence the process following its completion [9]. Among the factors that should be considered before starting an embryo transfer are time and stage of embryo transfer, embryo selection, choice of catheter, whether performing a trial embryo transfer before the actual transfer or not (mock or dummy embryo transfer), the transfer medium, performing ultrasound before transfer, the necessity of a full bladder, and the experience of the providers staff [10].

The influence of depth of embryo replacement into the uterine cavity has been postulated as being one of the most important factors contributing to the success of an IVF treatment. Traditionally, most IVF programs have relied on the clinician's "clinical touch" for the placing of the transfer catheter within the uterine cavity at a point near the fundus. Today this procedure has been modified to utilize ultrasound guidance to direct the placement of the catheter tip, allowing for more accurate placement [11]. It has been traditionally accepted that the embryo should be placed $10 \mathrm{~mm}$ below the endometrial surface, but others suggest placing the embryo rather lower in the uterine cavity may improve pregnancy rate [12]. A number of studies have demonstrated that depositing the embryos too near to the fundus has a negative effect on the outcome of IVF [13].

The best site of embryo deposition is still not clear and remains highly debated. This debate has been fuelled by conflicting results from published clinical trials [14]. One of the most important factors for successful embryo transfer is not touching the endometrium of the fundus with replacement of the embryo in the lumen of the uterine cavity in order to prevent any endometrial contraction with consequent embryo dislocation [15]. Interestingly blind catheter placement has been result in apposition of the catheter in $25 \%$ of the cases. Transabdominal ultrasound guidance may represent an important tool in this regard [16].

\section{Patients and methods}

It was a prospective study performed at Maternity Hospital, IVF Unit from December 2015 to October 2017. Patients were allocated randomly into either study group using a computergenerated random number list. The primary outcome measure was the incidence of clinical pregnancy.

All patients in the study had:

o Full history taking.

o Full general physical examination and local gynecological examination.

o Ultrasonographic examination.

\section{o IVF/ICSI}

Procedure: Long Protocol was used. It was started in luteal phase or follicular phase. This method is of choice when patients have to be grouped in batches for IVF.
Luteal phase: In this protocol GnRh analogs are started from luteal phases from around 21st day of the previous cycle. It was continued till a proper pituitary suppression is attended. Criteria for pituitary suppression are:

o $\quad \mathrm{LH}<5.0 \mathrm{IU} / \mathrm{ml}$,

o $\quad$ Estradiol $<50 \mathrm{pg} / \mathrm{ml}$,

o $\quad$ Progesterone $<1 \mathrm{ng} / \mathrm{ml}$.

o Pituitary suppression is usually confirmed by commencement of menstruation.

Follicular phase: GnRH analogues were started from first or second day of menstrual cycle and continued for down regulation. Stimulation was started any day to suit the oocyte retrieval as this protocol was done to adjust the cases in batches and continued till one day before hCG administration. Administration of agonist was discontinued on the day of hCG. Ovulation was triggered by injecting subcutaneously $10000 \mathrm{IU}$ of h CG when leading follicles reached $18 \mathrm{~mm}$ with appropriate serum estradiol levels. Transvaginal US-guided oocyte aspiration was performed approximately 36 hour after hCG injection under local anesthesia. ICSI were performed and after 5 days culture, one or two embryos were morphologically selected to be transferred in utero. Transvaginal progesterone was given daily for luteal phase support for 2 weeks, starting the day of embryo transfer.

Embryo transfer steps were Pre-ET trial transfer. Trans abdominal ultra sonographic guidance with full bladder. Cervical lavage with culture media to remove excess mucus. Practice transfer just through internal os. Wallace catheter, 40 microliter volume with 10 microliter air bubble Gentle insertion: manipulate cervix with Pedersen or graves speculum. Use ultrasonography to avoid catheter tip disrupting endometrium: avoid touching fundus. Inject embryos slowly $1.5 \mathrm{~cm}-2.0 \mathrm{cms}$ from fundus as confirmed by ultrasonography. Withdraw catheter slowly and turn through 90 degrees while withdrawal with piston depressed. Inspection of catheter by embryologist for blood, mucus, or retained embryos.

Inclusion criteria for both groups include:

I. Age of patient between 25-35 years.

II. Regular menstrual cycle.

III. Main causes of infertility attributable to tubal, idiopathic or male factor.

IV. FSH and LH Serum level on day 3 of the ovarian cycle is less than $12 \mathrm{IU} / \mathrm{L}$

V. Long agonist induction protocol was used.

VI. Embryos were transferred in blastocyst stage.

VII. Less than three embryos were replaced into the uterine cavity. 


\section{Global Journal of Reproductive Medicine}

\section{Exclusion criteria}

In order to minimize the incidence of factors potentially affecting embryo transfer and IVF outcome, certain criteria were used to exclude patients from the study including:

i. Presence of an abnormal uterine cavity due to various causes such as endometrial polyps, myomas, fibromas, endometrial synaechiae, etc. diagnosed by doing ultrasound or hystosalpinghogram.

ii. Presence of any systemic disease potentially reducing implantation rate such as autoimmune diseases and diabetes diagnosed by chemical tests.

Statistical Methods: Data were collected, tabulated, then analyzed on a personal commuter using IBM@ SPSS@ Statistics version 21 (IBM@ Corp., Armonk, NY). Normally distributed numerical data were presented as mean and SD and differences between the two groups were compared with the independentsamples t test. Skewed numerical data were presented as median and inter quartile range and inter-group differences were compared non-parametrically using the Mann-Whitney U test. Qualitative data were presented as number and percentage and the chi square test or Fisher's exact test, when appropriate, were applied for comparison of the two groups. A two-sided p-value $<0.05$ were considered statistically significant.

\section{Results}

Table 1: The clinic-demographic data of women under trial.

\begin{tabular}{|c|c|c|c|}
\hline & Group I & Group II & P-value \\
\hline Age (y) & $23.1 \pm 9.5$ & $24.1 \pm 8.9$ & $>0.05$ \\
\hline $\begin{array}{c}\text { Body mass } \\
\text { index }\end{array}$ & $21.5 \pm 2.1$ & $21.2 \pm 2.6$ & $>0.05$ \\
\hline Parity & $1.2 \pm 0.6$ & $1.4 \pm 0.4$ & $>0.05$ \\
\hline $\begin{array}{c}\text { Duration of } \\
\text { infertility }\end{array}$ & $7.9 \pm 3.2$ & $8.1 \pm 2.2$ & $>0.05$ \\
\hline \multicolumn{3}{|c|}{ Causes of infertility } \\
\hline Ovarian factor & 12 & 11 & $>0.05$ \\
\hline $\begin{array}{c}\text { Tubal factor } \\
\text { Endometriosis }\end{array}$ & 5 & 7 & $>0.05$ \\
\hline Male factor & 3 & 7 & $>0.05$ \\
\hline Unexplained & 3 & 2 & $>0.05$ \\
\hline FSH & $9.3 \pm 2.1$ & $8.8 \pm 2.9$ & $>0.05$ \\
\hline $\begin{array}{c}\text { Antral follicle } \\
\text { count }\end{array}$ & $6.3 \pm 2.3$ & $7.1 \pm 2.5$ & $>0.05$ \\
\hline
\end{tabular}

The 62 patients included in the analysis had comparable clinical characteristics, and no significant differences among subgroups could be noticed as far as age, BMI, infertility duration, main infertility cause, and indexes of ovarian follicular reserve (basal FSH and antral follicle count; AFC), were concerned (Table 1). The outcome of $\mathrm{COH}$ (total gonadotropin dose, number of retrieved oocytes, endometrial thickness) was similar in the four subgroups, and finally the mean number of transferred embryos did not differ among subgroups (Table 2). Significantly lower clinical pregnancy and implantation rates were observed in the subgroup II longer than $15 \mathrm{~mm}$ than when the embryos were released at less than $15 \mathrm{~mm}$ from the fundus (Table 2).

Table 2: Significantly lower clinical pregnancy and implantation rates were observed in the subgroup II longer than $15 \mathrm{~mm}$ than when the embryos were released at less than $15 \mathrm{~mm}$ from the fundus.

\begin{tabular}{|c|c|c|c|}
\hline & Group I & Group II & P-value \\
\hline $\begin{array}{c}\text { Total dose of } \\
\text { gonadotrophins }\end{array}$ & $1034 \pm 201$ & $1121 \pm 199$ & $>0.05$ \\
\hline Number of retrieved oocytes & $6.2 \pm 1.3$ & $6.1 \pm 2.1$ & $>0.05$ \\
\hline Number of fertilized oocytes & $4.1 \pm 1.1$ & $3.9 \pm 2.1$ & $>0.05$ \\
\hline $\begin{array}{c}\text { Endometrial thickness at } \\
\text { day of implantation }\end{array}$ & $10.4 \pm 1.5$ & $9.8 \pm 1.9$ & $>0.05$ \\
\hline $\begin{array}{c}\text { Number of transferred } \\
\text { embryos }\end{array}$ & $1.1 \pm 0.8$ & $1.1 \pm 0.6$ & $>0.05$ \\
\hline $\begin{array}{c}\text { Implantation rate } \\
\text { Abortion rate }\end{array}$ & 22.2 & 33.3 & $<0.05$ \\
\hline Pregnancies at 8 weeks & 7 & 4 & $<0.05$ \\
\hline
\end{tabular}

The abortion rate was noticeably (but not significantly) higher in case of embryo release close to the fundal endometrial surface (EFD $<5 \mathrm{~mm}$ ); as a consequence, in this subgroup of patients the ongoing pregnancy rate at 10 weeks was lower that the one observed for between 5 and $15 \mathrm{~mm}$ (Table 2). Overall, the ongoing pregnancy rate was higher in group I than group II because of a significantly poorer implantation rate, below $5 \mathrm{~mm}$ it was lower because a relevantly higher abortion rate (Table 2).

\section{Discussion}

Early studies considering the site of embryo replacement as a variable able to influence IVF success rate suggested that the best results could be obtained when embryos were injected placing the catheter tip as close as possible to the fundal endometrial surface, avoiding to touch the mucosa in order to prevent any endometrial contraction with consequent embryo dislocation [3]. Subsequent studies, however, did not confirm this finding. Differently, they observed a higher PR when the catheter tip was positioned in the middle of the uterine cavity, approximately $15 \mathrm{~mm}$ from the fundal endometrium [6]. In another study, an increment of $11 \%$ in the PR was reported for every single millimeter, from 0 to $5 \mathrm{~mm}$, of increasing distance of the embryo release site from the fundus of the cavity [15]. Further, a prospective cohort study comparing IVF outcome after upper uterine cavity vs. lower-to-middle uterine cavity ETs showed significantly better results when the embryos were released in the middle of the uterine cavity, approximately from 15 to $20 \mathrm{~mm}$ from the fundal endometrium [7]. Also a metaanalysis including three randomized prospective trials $[4,5,16]$ showed a higher pregnancy rate when embryos were replaced in the middle of the uterine cavity than when they were released close to the fundus [13]. 


\section{Global Journal of Reproductive Medicine}

Overall, most published reports suggested that replacing embryos between 10 and $20 \mathrm{~mm}$ from the fundal endometrium could lead to better IVF outcome than transferring them at other levels of the uterine cavity $[6,9,10,13]$. Most studies, however, estimated the pregnancy rate according to the placement of the catheter tip during embryo injection, without considering that the actual site at which embryos are placed is some mm closer to the uterine fundus than the catheter's tip. Moreover, a dislocation of the embryos in the few seconds following their release into the uterine cavity is possible, and is not rare. This event has been documented by studies that demonstrated that some technical conditions of embryo transfer are associated with a relevant risk of embryo displacement [17]. In order to better assess the actual site of embryo release, the most recent publications used the US localization of the air bubble that is visible just after embryo release instead of the visualization of the catheter tip [11,12]. A large retrospective study showed that no movement of the air bubble occurs in more than $90 \%$ of cases when the catheter is loaded with a low amount of culture medium [18]. In the present study, a low fluid amount $(20 \mu \mathrm{l})$ was used to load the catheter and a moderate injection speed was used, as recommended to avoid embryo displacement $[17,18]$.

A couple of studies using US detection of air bubble localization have been reported to date, but differently from ours they are both retrospective and include much less observations $[11,12]$. The first investigated the relationship between air bubble position and pregnancy rates in 315 blastocyst transfers, but differently from our study, the EFD was measured with trans-abdominal US [11]. The PR was found to be significantly lower when the EFD was longer than $10 \mathrm{~mm}$ [11]. The second study included 409 ETs and failed to demonstrate any significant difference in PR and IR that could be related to the site of embryo release [12]. In fact, both in case of transfer of cleavage stage and blastocyst stage embryos, the mean pregnancy rate in IVF cycles that led to conception and in those that did not was the same, and the PR and IR were comparable when the embryos were transferred in the upper or middle third of the uterine cavity [12].

The evidence available to date is, overall, quite conflicting and allows just to state that it is likely that the site of embryo transfer affects IVF outcome; most studies evaluated the embryo transfer in an approximate way (looking at the catheter's tip or using transabdominal US to detect the air bubble) and a well defined range within which embryos must be replaced is not yet been found. Herein we report the first large prospective study in which the impact of the site of deposition on IVF outcome was evaluated using transvaginal US detection of air bubble position, by far the most precise available method to detect embryo position inside the uterine cavity. Our data indicate that optimal PR, IR and ongoing PR may be obtained when embryos are released in the range between $5-5 \mathrm{~mm}$. if the distance from the fundus is longer than $15 \mathrm{~mm}$, a significant worsening of IVF outcome occurs. The results that we observed were confirmed when we performed data sub-analyses according to the type of treatment (conventional IVF or ICSI) or the number of embryos transferred (two or one). The overall IVF results observed in our study were similar to those published in the last available European report on IVF outcome for ICSI [19]. It must be underlined that our observations take into account the embryo morphological quality, the patients' baseline characteristics (including BMI and ovarian reserve), and the endometrial thickness, and therefore are likely to depend just on the site at which embryos were released.

\section{Conclusion}

In conclusion, it appears that embryo transfer between 5 and $15 \mathrm{~mm}$ from the uterine fundus, is the place where most pregnancies obtained with spontaneous conception may be found during the first US examination at 6-7 weeks, and is likely to be the place where the endometrium displays the best receptivity.

\section{References}

1. Hearns SRM, Miller BT, Scott L, Creuss D, Chakraborty PK, et al. (2000) Pregnancy rates after embryo transfer depend on the provided at embryo transfer. Fertil Steril 74(1): 80-86.

2. Fanchin R, Righini C, Olivennes F, Taylor S, de Ziegler D, et al. (1998) Uterine contractions at thetime of embryo transfer alter pregnancy rates after in-vitro fertilization. Hum Reprod 13(7): 1968-1974.

3. Waterstone J, Curson R, Parson J (1991) Embryo transfer to low uterine cavity. Lanset 337(8754): 1413

4. Coroleu B, Barri PN, Carreras O, Martinez F, Parriego M, et al. (2002) The influence of the depth of embryo replacement into the uterine cavity on implantation rates after IVF: a controlled, ultrasound-guided study. Hum Reprod 17(2): 341-346.

5. Eijkemans MJ, Heijnen EM, De Klerk C, Habbema JD, Fauser BC (2006) Comparison of different treatment strategies in IVF with cumulative live birth over a given period of time as the primary end-point: methodological considerations on a randomized controlled noninferiority trial. Hum Reprod 21(2): 344-351.

6. Nazari A, Askari HA, Check JH, O'Shaughnessy A (1993) Embryo transfer technique as a cause of ectopic pregnancy in in-vitro fertilisation. Fertil Steril 60 (14): 919-921.

7. MMWR Surveill Summ (2007) Assisted reproductive technology surveillance. United States 56(6): 1-22.

8. Al-Shawaf T, Dave R, Harper J, Linehan D, Riley P, et al. (1993) Transfer of embryos intothe uterus: how much do technical factors affect pregnancy rates? J Assist Reprod Genet 1 (1): 31-36.

9. Guerif F, Bidault R, Gasnier O, Couet ML, Gervereau O, et al. (2004) Efficacy of blastocyst transfer after implantation failure. Reprod Biomed Online 9(6): 630-636.

10. Abou-Setta AM, Mansour RT, Al-Inany HG, Aboulghar MM, Aboulghar MA, et al. (2007) Among women undergoing embryo transfer, is the probability of pregnancy and live birth improved with ultrasound guidance over clinical touch alone? A systemic review and metaanalysis of prospective randomized trials. Fertil Steril 88(22): 333341.

11. Ivanovski M, Damcevski N, Radevska B, Doicev G (2012) The influence of the depth of embryo replacement into the uterine cavity on in-vitro fertilization outcome. Akush Ginekol (Sofia) 51(43): 59-67. 
12. Kovacs GT (1999) What factors are important for successful embryo transfer after I.V.F ? Hum Reprod 14(4): 590-592.

13. Mains L, Van VBJ (2010) Optimizing the technique of embryo transfer. Fertil Steril 94 (31): 785-790.

14. Kumar D (2007) Prevalence of female infertility and its socio-economic factors in tribal communities of Central India. Rural Remote Health $7(2): 456$.

15. Mansour R (2005) Minimizing embryo expulsion after embryo transfer: a randomized controlled study. Hum Reprod 20(1):170-174.

16. Margalioth EJ, Ben-Chetrit A, Gal M, Eldar-Geva T (2006) Investigation and treatment of repeated implantation failure following IVF-ET. Hum Reprod 21(12): 3036-3043.
17. Schoolcraft WB, Surrey ES, Gardner DK (2001) Embryo transfer: techniques and variables affecting success. Fertil Steril 76: 863-870.

18. Rovei V, Dalmasso P, Gennarelli G, Lantieri T, Basso G, et al. (2013) IVF outcome is optimized when embryos are replaced between 5 and $15 \mathrm{~mm}$ from the fundal endometrial surface: a prospective analysis on 1184 IVF cycles. Reprod Biol Endocrinol 11(83): 114-119.

19. Sallam HN (2005) Embryo transfer: factors involved in optimizing the success. Curr Opin Obstet Gynecol 17(3): 289-298.

\section{Your next submission with Juniper Publishers} will reach you the below assets

- Quality Editorial service

- Swift Peer Review

- Reprints availability

- E-prints Service

- Manuscript Podcast for convenient understanding

- Global attainment for your research

- Manuscript accessibility in different formats

(Pdf, E-pub, Full Text, Audio)

- Unceasing customer service

Track the below URL for one-step submission https://juniperpublishers.com/online-submission.php 